\title{
Strength variability of single flax fibres
}

\author{
Aslan, Mustafa; Chinga-Carrasco, G.; Sørensen, Bent F.; Madsen, Bo
}

\section{Published in:}

Journal of Materials Science

Link to article, DOI:

10.1007/s10853-011-5581-x

Publication date:

2011

Link back to DTU Orbit

Citation (APA):

Aslan, M., Chinga-Carrasco, G., Sørensen, B. F., \& Madsen, B. (2011). Strength variability of single flax fibres. Journal of Materials Science, 46(19), 6344-6354. https://doi.org/10.1007/s10853-011-5581-x

\section{General rights}

Copyright and moral rights for the publications made accessible in the public portal are retained by the authors and/or other copyright owners and it is a condition of accessing publications that users recognise and abide by the legal requirements associated with these rights.

- Users may download and print one copy of any publication from the public portal for the purpose of private study or research.

- You may not further distribute the material or use it for any profit-making activity or commercial gain

- You may freely distribute the URL identifying the publication in the public portal

If you believe that this document breaches copyright please contact us providing details, and we will remove access to the work immediately and investigate your claim 
Editorial Manager(tm) for Journal of Materials Science Manuscript Draft

Manuscript Number: JMSC22209R1

Title: Strength Variability of Single Flax Fibres

Article Type: Manuscript (Regular Article)

Keywords: Fibre morphology; Tensile properties; Microscopy; Natural fibre composites

Corresponding Author: Mustafa Aslan, Msc

Corresponding Author's Institution: Material Science

First Author: Mustafa Aslan, Msc

Order of Authors: Mustafa Aslan, Msc;Gary Chinga-Carrasco;Bent F. Sørensen;Bo Madsen

Abstract: Due to the typical large variability in the measured mechanical properties of flax fibres, they are often employed only in low graded composite applications. The present work aims to investigate the reasons for the variability in tensile properties of flax fibres. It is found that the inaccuracy in the determination of the cross sectional area of the fibres is one major reason for the variability in properties. By applying the typical circular fibre area assumption, a considerable error is introduced into the calculated mechanical properties. Experimental data, together with a simple analytical model, are presented to show that the error is increased when the aspect ratio of the fibre cross sectional shape is increased. The variability in properties due to the flax fibres themselves is found to originate from the distribution of defects along the fibres. Two distinctive types of stress-strain behaviour (linear and nonlinear) of the fibres are found to be correlated with the amount of defects. The linear stress-strain curves tend to show higher tensile strength, higher Young's modulus, and lower strain to failure than the nonlinear curves. Finally, the fibres are found to fracture by a complex microscale failure mechanism. Large fracture zones are governed by both surface and internal defects; and these cause cracks to propagate in the transverse and longitudinal directions. 


\section{Revision of manuscript submitted to Journal of Materials Science \\ Reference Number JMSC22209 \\ "Strength Variability of Single Flax Fibres" by Aslan et al.}

\section{Dear Editor}

The authors would like to thank the two referees for their constructive comments. The authors have now carefully considered each of the referees' reports which are shown in italic and have taken them into account as described below.

\section{$\underline{\text { Reviewer \#1 }}$}

This is a well-written paper which presents important results with clarity. It complements two papers I have recently seen in refereeing:

(1) Thomason et al on 'fibre cross section determination and variability in sisal and flax and its effect on fibre performance characterization' (Composites Science and Technology CSTE-D-1100016) who conclude that 'fibre "diameter" measurement is not an attractive method for accurate estimation of cross sectional area of these natural fibres', and (2) Virk et al on 'the tensile properties of jute / epoxy UD composite' (JMSC21072/JMSC21073) where they derive a 'fibre area correction factor' of 1.42 for jute fibres, then use the parameter in the rules-of-mixture for both moduli and strength to provide more accurate predictions of composite properties from their own data and that of others.It would be interesting to see how the data in this scandinavian manuscript for flax compares with that for flax from Strathclyde and for jute from Plymouth, but that is perhaps a separate paper.

The proposed two papers are indeed relevant for the present paper, and their findings have therefore been included in the new version of the paper. The citations can be seen at page 2, line 29; page 7, line 43 and line 59.

The data on the flax fibres is vague. It is good practice to give the flax variety and/or accession and country of growth if available, but failing that then surely an Ekotex batch number is available? Are the green fibres and the cottonized fibres from the same field of flax or quite separate plants?

We have modified the fibre information accordingly at page 3, line 9-13. 
(3)

Reference 8 should be Virk AS, Hall W, Summerscales J (not Amandeep, Wayne and Summerscales).

This has been changed.

(4)

There are a few phrases which would benefit from sub-editing by a native English speaker.

The manuscript has been corrected by a native English speaker, resulting in a number of grammatical corrections.

\section{$\underline{\text { Reviewer \#2 }}$}

This is a useful contribution to this subject area. There is little doubt that there are issues surrounding the variability in fibre properties and this study is a useful contribution to the debate.

It is for this reason that studies of textile fibres use the linear density method of measurement rather than relying upon the dubious notion of a regular (and circular) cross section. This needs to be mentioned in the text.

The authors believe that the linear density method which uses the linear density of a textile yarn as an indirect measure of its cross sectional area can not be used for single flax fibre due to their short lengths (few millimetres).

With respect to the occurrence of defects in the fibres, the paper states that these are presumed to act as defects. A recent review article in Journal of Biobased Materials and Bioenergy (Hill and Hughes JBMBE, 4, 148-158, 2010) refers to these defects and how this leads to poor material properties in the composites due to stress concentrations in the matrix at the defect sites, also there is mention of the non-linear stress strain behaviour in uniaxial composites. It is worth referring to this article in the submitted paper.

We welcome the suggestion of referring to this relevant paper. The text has been modified accordingly at page 10 , line 33-37. 


\title{
Strength Variability of Single Flax Fibres
} Mustafa Aslan ${ }^{1 *}$, Gary Chinga-Carrasco ${ }^{2}$, Bent F. Sørensen ${ }^{1}$, Bo Madsen ${ }^{1}$

${ }^{1}$ Materials Research Division, Risø National Laboratory for Sustainable Energy, Technical University of Denmark, Frederiksborgvej 399, DK-4000 Roskilde, Denmark *muas@ risoe.dtu.dk

${ }^{2}$ Paper and Fibre Research Institute, Høgskoleringen 6b, NO-7491 Trondheim, Norway

\begin{abstract}
Due to the typical large variability in the measured mechanical properties of flax fibres, they are often employed only in low grade composite applications. The present study aims to investigate the reasons for the variability in tensile properties of flax fibres. It is found that an inaccuracy in the determination of the cross sectional area of the fibres is one major reason for the variability in properties. By applying a typical circular fibre area assumption, a considerable error is introduced into the calculated mechanical properties. Experimental data, together with a simple analytical model, are presented to show that the error is increased when the aspect ratio of the fibre cross sectional shape is increased. A variability in properties due to the flax fibres themselves is found to originate from the distribution of defects along the fibres. Two distinctive types of stress-strain behaviours (linear and nonlinear) of the fibres are found to be correlated with the amount of defects. The linear stress-strain curves tend to show a higher tensile strength, a higher Young's modulus, and a lower strain to failure than the nonlinear curves. Finally, the fibres are found to fracture by a complex microscale failure mechanism. Large fracture zones are governed by both surface and internal defects; and these cause cracks to propagate in the transverse and longitudinal directions.
\end{abstract}

Keywords: Fibre morphology, Tensile properties, Microscopy, Natural fibre composites 


\section{Introduction}

The utilisation of renewable resources is of crucial importance for advancing towards a sustainable way of producing materials. Natural fibres are renewable resources that are used in a wide range of industrial applications such as textiles and increasingly in polymer composites, as an alternative to synthetic fibres. Flax fibres (Linum usitatissimum) are widely studied plant-based natural fibres for use as reinforcement in polymer matrix composites [1-7].

Flax fibres are known to show a large variability in their measured mechanical properties [2, 3]. Due to uncertainties about the reasons for the variability of fibre properties, and the influence of this variability on the final mechanical properties of the composites, flax fibres are often employed only in low grade composite applications [4]. The variability in fibre properties can be ascribed either to the variability introduced by the applied experimental characterisation method, or to the inherent variability of the flax fibres themselves. A typical approach of evaluating the cross sectional area of the fibres as being circular, and to use the measured fibre "diameter" to calculate the cross-sectional area is a rough approximation since the fibres have a polygonal shape [3,5-8]. Furthermore, the fibres are known to vary in their cross sectional area along the fibre length [9]. Altogether, any uncertain evaluation of the cross sectional area brings a variation into the determined mechanical properties of the fibres [10]. In addition, flax fibres are delicate materials with cross sectional dimensions in the order of micrometers, and a few millimeters in length; this enhances measurement errors during the mechanical testing of the fibres. Flax fibres themselves show variability in their cell wall structure due to variations in growth conditions, different levels of maturity of the fibres, as well as due to the non-uniformity of the retting and decortication processes applied to extract the fibres from the plants. One type of structural characteristics in flax fibres are the so-called kink bands which are regions of the cell wall with a disordered organisation of the cellulose microfibrils in the matrix of hemicellulose and lignin. The kink bands are formed both naturally during growth, and artificially during fibre processing. The kink bands are presumed to act as defects influencing the mechanical behaviour of the fibres [2].

The aim of the present study is to investigate the various reasons for the variability in mechanical properties of single flax fibres. The experimental based investigations include analyses of the applied method for determination of the cross sectional area of the fibres, together with analyses of the different types of stress-strain behaviours, and fracture behaviours of the fibres. An attempt is made to correlate the latter two types of mechanical behaviours with the defect regions of the fibres. 


\section{Material and Methods}

Materials

The flax fibres (Linum usitatissimum) were supplied by Ekotex, Poland. Two types of differently processed fibres were used. The two types of fibres were originating from different fields, and as such they are not coming from the same batch.

Green fibres: These fibres were obtained from plant stems that have been harvested with no further processing. Single fibres were carefully separated from the stems by hand.

Cottonized fibres: After the plant stems were harvested, they were kept in the field for retting. Afterwards, the fibre bundles in the outer part of the stems were separated from the broken shives in the core part by a decortication process where the stems were crushed and beaten by passing them between rotating wheels equipped with blunt knives. Next, the coarse fibre bundles were combed in a hackling process in order to get straightened fibres and thinner fibre bundles. Finally, to further disintegrate the fibre bundles into single fibres, they were cottonized by a mechanical process $[11,12]$. Single fibres were separated carefully from the fibre bundles by hand.

Measurement of cross sectional area of fibres

A precise determination of the cross sectional area of the fibres is crucial for the calculation of the correct tensile stress values. Since the fibres have irregular polygonal shapes, errors can easily arise in the cross sectional measurements. In the present study, the cross sectional area of the fibres was measured with two different methods: Method 1: Circular fibre area measurements

An optical microscope (Aristomet, Leitz) equipped with polarized filters, and image analysis software (Image-Pro Plus 5.0) was used to measure the fibre width with an accuracy of $\pm 0.1 \mu \mathrm{m}$ at 9 positions along the fibres within a gauge length of $5 \mathrm{~mm}$ (see Fig 1). The cross sectional area was calculated by assuming a circular cross-section. Method 2: True fibre area measurements

The fibres were placed in a plastic holder to avoid tilted cross sections, and to align the fibres. The fibres were then embedded in epoxy resin (EpoFix, Struers). The embedded fibre samples were ground and polished as described by Reme et al. [13]. A series of cross-sectional images were acquired at different locations using a Hitachi S-3000 variable pressure scanning electron microscope with a solid-state backscattered detector. The digital images were 
processed automatically with the PFI Fibre Cross-Section ImageJ plugin (version 3k). The images were thresholded. Touching fibres, fibre agglomerates and apparently misaligned fibres were removed by applying a combination of size, form factor and solidity shape measurements (see Fig. 2), as described by Chinga-Carrasco et al. [14].

Figure 3 shows a schematic drawing of the cross sectional areas that were determined by the two different methods. $\mathrm{A}_{\text {circ }}$ is the circular fibre area determined by Method 1. $\mathrm{A}_{\text {true }}$ is the true fibre area and $\mathrm{A}_{\text {lum }}$ is the area of the lumen determined by Method 2. The cell wall area is given by $A_{c w}=A_{\text {true }}-A_{\text {lum. }}$. In addition, in Method 2, the shape of the fibre cross-sections was quantified by their aspect ratio, which is the ratio between the major and minor axis of a fitted ellipse with an area equivalent to the fibre cross sectional area, and with the same first and second degree moments (Image-Pro Plus 5.0). The aspect ratio is always $\geq 1$.

\section{Tensile testing of fibres}

Single flax fibres were inspected with an optical microscope in order to exclude double fibres, and highly deformed and twisted fibres. Since the fibres are too delicate for manual handling, cardboard was used as a specimen holder to facilitate the testing. The fibre ends were fixed to the cardboard using cyanoacrylate glue. Prior to the tensile testing, using the optical microscope, the average fibre width was determined from 9 width measurements along the $5 \mathrm{~mm}$ gauge length, and the circular fibre area was calculated (Method 1). The cardboard was gripped in the plastic grips of the tensile test machine (ElectroPuls E3000, Instron) close to the places where the fibre was mounted. The cardboard was then cut on both sides of the central hole. The tensile tests were performed with a constant cross head speed of $0.5 \mathrm{~mm} /$ minute. The load was measured using a $50 \mathrm{~N}$ load cell. The testing was done according to the ASTM D 3379 at an ambient temperature of about $23^{\circ} \mathrm{C}$ and a relative humidity of about $55 \%$. Figure 4 shows the testing configuration used. In total, 35 Green fibres, and 50 Cottonized fibres were successfully tested (15 Green fibre samples were discarded due to failure nearby the glue region).

Fracture surface of fibres

The fracture surfaces of the tensile tested fibres were examined in an environmental scanning electron microscope (ESEM, Zeiss). In addition, detailed surface images of intact fibres were acquired with an ultra field-emission SEM (FESEM, Zeiss) in the secondary electron mode. 


\section{Results \\ Cross sectional area}

Figure 5 shows the cross sectional area distributions that were determined for single flax fibres (Cottonized fibres) using the two different measurement techniques, Method 1 and Method 2. The results obtained using the circular fibre area measurements (Method 1) are in the same range as the true fibre area measurements (Method 2). For both methods, $95 \%$ of fibres were distributed in the range of 100 to $650 \mu \mathrm{m}^{2}$. However, the distribution of Method 1 is shifted to the right of the distribution for Method 2 with mean \pm stdv. fibre areas of $327 \pm 128$ and $236 \pm 115 \mu \mathrm{m}^{2}$, respectively (Table 1). Thus, on an average basis, the area of fibres determined by Method 1 is $39 \%$ higher than the area determined by Method 2; see however the results below about the influence of the fibre shape.

Figure 6a shows that the lumen content (ratio of the lumen area to the true fibre area) of the fibres is typically very small although some large values of lumen content were found. Hence, it is found that $85 \%$ of all fibres show a lumen content below $1 \%$. The mean lumen content is $1.6 \%$.

The distribution of aspect ratios of the shape of fibre cross-sections is presented in Figure 6b. Distributions are shown for fibres with lumen and without lumen. The aspect ratios are in the range of 1.0 to 2.3 and with means \pm stdvs. of $1.45 \pm 0.27$ and $1.40 \pm 0.12$, for fibres with lumen and without lumen, respectively. The grand mean \pm stdv. aspect ratio of all fibres is $1.42 \pm 0.26$.

The results presented in Table 1 are for two large groups of fibres that did not consist of the exact same fibres. In order to compare the measurements of the exact same fibres, one group of 6 fibres was randomly selected. The circular area of each of the fibres was first determined by Method 1, and then the fibres were embedded in epoxy resin and the true area of each of the fibres was determined by Method 2 at several locations along the fibres. The measured cross sectional areas and aspect ratios for these 6 fibres are shown in Table 2. It is seen that the percentage difference (in absolute values) in the area measurements between the two methods is consistently increased when the aspect ratio of the fibres is increased. For a low aspect ratio of 1.1 , the area difference is only $3 \%$, whereas the area difference is $37 \%$ for a high aspect ratio of 1.9. The results also point towards that the area determined by Method 1 is being overestimated for fibres with low aspect ratios, and it is being underestimated for fibres with high aspect ratios. The threshold aspect ratio is in the range of about 1.5 to 1.8 . 


\section{Stress-strain behaviour}

Initially, all the measured stress-strain curves were evaluated based on their curve shapes. The curves evaluated as being a result of experimental errors were excluded from further analysis. Figure 7 shows typical examples of such erratic curves. Several factors such as twisted fibres, double fibres, pre-loaded fibres and fibre slip from the glue are assumed to be the cause of these experimental errors. For the Cottonized fibres, 15 out of 50 stress-strain curves (30 $\%$ ) were excluded due to such experimental errors. For the Green fibres, 5 out of 35 stress-strain curves (14 \%) were excluded.

Besides the above-mentioned experimental error curves, it was found that the flax fibres show a distinctive variation in their stress-strain behaviour. Typical stress-strain curves for the Green and the Cottonized fibres are shown in Figure 8. All the measured fibres were grouped based on the two distinctive stress-strain behaviours: (1) nearly linear stress-strain behaviour, and (2) nonlinear stress-strain behaviour. Interestingly, the linear stress-strain behaviour was the only curve type seen for the Green fibres, whereas both curve types were almost equally represented by the Cottonized fibres (see Table 3).

The values of tensile strength, Young's modulus and strain to failure were obtained from the stress-strain curves. The results are summarized in Table 3 by grouping them according to fibre type and stress-strain curve type. The following comparisons are made based on the mean values to show the trends of the results. For the Cottonized fibres, the nonlinear type of stress-strain curves exhibit a lower tensile strength (641 vs. $760 \mathrm{MPa}$ ), a lower Young's modulus (24.2 vs. $33.1 \mathrm{GPa})$, and a higher strain to failure (2.50 vs. $2.27 \%)$ than the linear type of curves. Based on the results from the linear curves, the Green fibres showed a higher tensile strength ( $974 \mathrm{vs.} 760 \mathrm{MPa}$ ), and a higher strain to failure (3.00 vs. $2.27 \%$ ) than Cottonized fibres. However, the relatively large variability of the measurements is shown by the large values of stdvs. which gives coefficient of variations $(\mathrm{CV}=\mathrm{stdv} / \mathrm{mean})$ in the range of $20-50 \%$.

Fracture behaviour

Figure 9 shows typical examples of the two types of defects seen on the surface of flax fibres: (i) transverse defects, which are the most visible type of defects and (ii) longitudinal defects. These two types of defects, which are introduced to the fibres both naturally during growth and artificially during processing, are found in the present study to control the fracture behaviour of the fibres. 
On a macroscopic level, by observing the stress-strain curves of the fibres (see Figure 8), it appears that the fibres fracture in a brittle manner. However, microscopic investigations have revealed that the fracture of the fibres occurs in a more ductile and complex manner by longitudinal splitting over a large area. Figure 10a shows an example of a flax fibre that was observed by optical microscope before and after a tensile test. Large surface transverse defects and small internal transverse defects were visible in the microscope before the test. Based on the observations of the fractured fibre ends (Figure 10a), it is believed that the fibre starts to fracture at one ( the largest) defect and then it continues to split until faced with the next defect along the fibre length as shown by the schematic view in Figure $10 \mathrm{~b}$.

Figure 11 shows an example of a fibre that has a large fracture zone. It is apparent that the fibre was split into smaller microfibrillar units at both fractured ends. It is believed that the fibre fracture started at the outer fibre surface in a transverse direction, and then it propagated in a longitudinal direction inside the cell wall layers.

\section{Discussion \\ Cross sectional area}

The results show that the cross sectional areas measured by the two methods on two large groups of fibres are within the same range of area distribution (see Figure 5). It can therefore be argued that the two groups of fibres are representative of identical and comparable sub-groups; i.e. the sampling of fibres in the two groups is unbiased. The difference between the mean values suggests that the circular fibre area measured by the Method 1 is overestimating the true fibre area by $39 \%$. This value compares very well with the value of $42 \%$ found from similar measurements on bundles of jute fibres in the study by Virk [6]. Furthermore, in a study of kenaf, bamboo, and curaua fibres, Teresaki et al. [15] demonstrated that the fibre area determined by the circular assumption is higher than the true fibre area, which was measured by laser scanning microscopy. The results in the present study, however, for the cross sectional areas measured for the same fibres (Table 2), shows that the fibre area is only slightly overestimated by Method 1 for fibres having a low aspect ratio, and that the fibre area was much underestimated for fibres having an aspect ratio above a given threshold value. This is supported by the examples shown in Table 4 of different cross sectional shapes of flax fibres and their measured aspect ratios. Altogether, it is demonstrated that the aspect ratio must be taken into account when considering the accuracy of the widely used Method 1. Similar considerations were made in the study by Thomason et al. [5]. 
As a consequence of the above considerations, it can be seen that the tensile strengths of the fibres, which were evaluated based on a circular assumption (Method 1), is likely to be either overestimated or underestimated depending on their aspect ratios. In general, the tensile strength will be determined with less accuracy for fibres having a high aspect ratio. The magnitude of the error can be estimated by approximating the cross sectional shape of the fibres to be elliptical with dimensions of the minor and major axes a and $b$, respectively. Then, the true cross sectional area is

$$
A_{\text {true }}=\pi \frac{1}{4} a b \quad(a \leq b)
$$

Then, at the point of maximum applied force, $\mathrm{P}$, the true tensile strength, is

$$
\sigma_{\text {true }}=\frac{P}{A_{\text {true }}}=\frac{P}{\pi \frac{1}{4} a b}
$$

Assuming (incorrectly) that the fibre has a circular cross section, and by measuring the fibre width, the crosssectional area may be calculated wrongly. In the two most extreme cases, the cross sectional area can be estimated from the minor axis, a, and the major axis, b, respectively. Then, the cross sectional areas are calculated to be

$$
A_{\min }=\pi \frac{1}{4} a^{2} \quad \text { and } \quad A_{\max }=\pi \frac{1}{4} b^{2}
$$

so that the tensile strength would be calculated as

$$
\sigma_{\max }=\frac{P}{A_{\min }}=\frac{P}{\pi \frac{1}{4} a^{2}} \quad \text { and } \quad \sigma_{\min }=\frac{P}{A_{\max }}=\frac{P}{\pi \frac{1}{4} b^{2}}
$$

where the subcripts max and min refer to the maximum and minimum values, respectively. Combining Equations (2) and (4), the ratio between the strengths assuming a circular cross section and the (true) elliptical cross section can be calculated. The result is

$$
\frac{\sigma_{\max }}{\sigma_{\text {true }}}=\frac{b}{a} \quad \text { and } \quad \frac{\sigma_{\min }}{\sigma_{\text {true }}}=\frac{a}{b}
$$

Figure 12 shows these upper and lower strength ratios as a function of the aspect ratio, b/a. The effect is quite significant. For instance, for a moderate aspect ratio of 1.25 , the strength ratios are 0.8 and 1.25 . Thus, the uncertainty in the strength value exceeds $\pm 20 \%$. For an aspect ratio of 2.3 (about the upper bound of aspect ratio found in the present study), the strength ratios are 0.43 and 2.3 respectively. For this situation, the calculated tensile 
strength value - obtained by assuming a circular cross section - may be in error by more than $50 \%$. If only an uncertainty of $10 \%$ is accepted then b/a must be below 1.10 .

The results in Table 2 of measured fibre areas by Method 1 and 2 can be used to calculate the error of the experimental tensile strength values found in the present study. The relative area difference, $\Delta_{\text {area }}$, between the two fibre areas is given by the equation

$$
\Delta_{\text {area }}=\frac{A_{\text {circ }}-A_{\text {true }}}{A_{\text {true }}}=\frac{A_{\text {circ }}}{A_{\text {true }}}-1
$$

An expression for the ratio between the experimental and true tensile strength can then be found

$$
\frac{\sigma_{\text {circ }}}{\sigma_{\text {true }}}=\frac{A_{\text {true }}}{A_{\text {circ }}}=\frac{1}{\Delta_{\text {area }}+1}
$$

The equation is used to calculate the strength ratios $\left(\sigma_{\text {circ }} / \sigma_{\text {true }}\right)$ of the 6 fibres in Table 2 , and the results are shown as data points in Figure 12. This demonstrates that the experimentally found errors in strength values are well located within the upper and lower bounds of the model lines.

In addition to the above considerations of fibre aspect ratio, it is also important to consider how the determined strength of the fibres is influenced by their lumen content. When the apparent fibre area is used to calculate the strength values, it necessarily means that in the case of fibres with a large variation in lumen content, the strength values will equally show a large variability. To avoid this, the absolute fibre area (i.e. the cell wall area) should be used in the calculation of strength. However, this can only be done by direct methods such as the one used in Method 2. For the flax fibres in the present study, the lumen content was found to be very low with a mean of $1.6 \%$ although some fibres have large lumen contents, and where about $85 \%$ of all the fibres were found to have lumen content below 1\%. In addition, it was found that the shape of the fibres, given by their aspect ratio, was not influenced by the fibres having a lumen. Hence, it can be stated that in the present study the variability of strength values is not influenced by the lumen content of the fibres. This is supported by a previous study by Charlet et al. [9] where it was shown that the lumen content of flax fibres rarely exceeds $8 \%$ and that the variation of mechanical properties is only slightly influenced by changes in the lumen content. 


\section{Stress-strain behaviour}

The observed nonlinear stress-strain behaviour is likely to be the result of the re-arrangement of the cellulose microfibrils in the fibre cell wall during loading. Baley [7] recorded a similar nonlinear behaviour of flax fibres, and noted that the fibres started to show a linear behaviour after the first loading cycle, which was ascribed to a presumptive change of the microfibril angle during loading. Others have also reported that the stress-strain curves can be seen as having either a linear elastic behaviour or a nonlinear strain hardening behaviour [16, 17]. In the present study, the Cottonized fibres showed both linear and nonlinear stress-strain behaviours, whereas the Green fibres showed only a linear behaviour. This difference between the two fibre types might be explained by the previous finding that the highly-processed Cottonized fibres have many more defects than the low-processed Green fibres [18] (see Figure 13), which possibly is caused by the stable growth of distributed damage. In other studies, it has been found that the microfibril angle is higher in defect regions than in non-defect regions [19-21], and this will lead to the hypothesis that more defective fibres will show more frequently a nonlinear stress-strain behaviour. This hypothesis is supported by the findings in the present study. Although, the proposed structure-property relationship needs more experimental verification, it is an interesting idea that the stress-strain behaviour of flax fibres can be used as a quantitative measure of their defect content. Furthermore, with the perspective of using flax fibres as reinforcement in composites, it can be mentioned that a similar nonlinear behaviour has been observed for the axial tensile stress-strain behaviour of unidirectional flax fibre/ polyester resin composites [22]. As discussed earlier, the large scatter in mechanical properties can be attributed (partly) to the use of the circular fibre area; an error which is increased when the aspect ratio of the fibres is increased. In addition to this, the large scatter in mechanical properties is likely also to be attributed to the distribution of defects (or kink bands) along the fibres (see Figure 13). Large defects lead to low mechanical properties, whereas smaller defects result in less reduced mechanical properties. A full quantitative understanding of the relationship between the size and number of defects and the mechanical properties of the fibres is still to be established, although a few studies have presented work on this [8, 23]. In the present study, despite the large scatter in mechanical properties, the results show as anticipated that the low-processed Green fibres tend to have a higher strength and a higher strain to failure than the highly-processed Cottonized fibres.

The measured values of tensile strength, Young's modulus and strain to failure in the present study are generally in good agreement with data from the literature as shown in Table 5. It can be seen that the three parameters for 
Fracture behaviour

It is obvious that the appearance of defects in an optical microscope (OM) image and in a scanning electron microscope (SEM) image (see Figures 9, 10 and 13) is different. It is possible to identify fibre defects with the SEM when the defects are shown as clear transverse marks (denoted kink bands) on the fibre surface. However, other types of defects are not visible on the fibre surface with the SEM, but they are clearly visible with the polarized OM. This suggests that these latter defects are located inside the fibres. Thus, a polarised OM is presently the most suitable imaging technique for investigating how the mechanisms of crack initiation and propagation are controlled by surface and/or internal defects.

It appears from the polarized OM micrographs that transverse defects can be sites of crack initiation. The observations of the fracture behaviour of the fibres suggest that they exhibit a brittle transverse failure in the outer surface, whilst the longitudinal microfibrillar splitting propagates inside the fibres. Previous studies have presented SEM micrographs of fracture surfaces $[23,26]$, but with no clear indication as to which type of defect caused the fibre fracture. However, based on the OM and SEM images in the present study, a mechanism is suggested to explain how both the surface and internal defects are controlling the fracture behaviour. The fact that the microscale failure mechanism is complex may explain why the strength variation of the flax fibres may not always follow a Weibull distribution [27]. The large fracture area formed in a complicated way is due to cell wall defects and anisotropy of internal fibre structures. This is in contrast to crack growth in brittle ceramics and glass fibres, which fail by unstable crack growth once a crack has initiated from a defect. 


\section{Conclusions}

Single flax fibres were investigated to find the reasons for the large variability in their measured mechanical properties. The major reasons for the variability were found to be:

- Inaccuracy in the determination of the cross sectional area of the fibres. By using the circular fibre area assumption, a considerable error is introduced into the calculated mechanical properties. Experimental data, together with a simple analytical model, are presented to show that the error is increased when the aspect ratio of the shape of fibre cross sections is increased. Thus, the aspect ratio of the fibres must be taken into account to improve the accuracy (and to reduce the variability) of the mechanical properties.

- Two distinctive types of stress-strain behaviour (linear and nonlinear) of the fibres. The linear stress-strain curves were found to give a higher tensile strength, a higher Young's modulus, and a lower strain to failure than the nonlinear curves. It was suggested that the two types of stress-strain behaviour were correlated with the amount of defects; the low-processed Green fibres revealed only the linear behaviour whilst the highly-processed Cottonized fibres show both the linear and the nonlinear behaviour.

- Complex fracture behaviour. The fibres were found to fracture by a complex microscale failure mechanism with large fracture zones governed by both surface and internal defects causing cracks to propagate in the transverse and longitudinal directions. A distribution in the size and number of defects along the fibres will lead to variability in the tensile strength obtained.

Altogether, it is recommended to furthermore investigate the correlation between the fibre defects and the mechanical performance of the fibres. It is believed that this will lead to an improved confidence in the use of flax fibres for reinforcement in polymer matrix composites.

\section{Acknowledgements}

The authors gratefully acknowledge Stergios Goutianos and Hans Lilholt for helpful advices and Shahid Mehmood for technical assistance, and for valuable input on fibre defects. The research has been partly funded by the European Community's Seventh Framework Programme under grant agreement no 214467 (NATEX), and grant no 274-07-0300 (WoodFibre3D) by the Danish Agency for Science, Technology and Innovation. 


\section{References}

1. Meijer WJM, Vertregt N, Rutgers B, Van de Waart M (1995) Ind Crops Prod 4:273-284

2. Bos HL, Van den Oever MJA, Peters OCJJ (2002) J Mater Sci 37:1683-1692

3. Joffe R, Andersons J, Wallstrom L (2003) Comp Part A 34:603-612

4. Bledzki K, Gassan SJ (1999) Prog Polym Sci 24: 221-274

5. Thomason JL, Carruthers J, Johnson KG (2011) Comp Sci Tech, In Press

6. Virk AS (2010) PhD thesis, University of Plymouth, United Kingdom

7. Baley C (2002) Comp Part A 33:939-948

8. Davies GC, Bruce DM (1998) Textile Res J 68:623-629

9. Charlet K, Baley C, Morvan C (2007) Comp Part A, 38:1912-1921

10. Virk AS, Hall W, Summerscales J (2010) Comp Sci Tech 50:995-999

11. Cierpucha W, Kozlowski R, Mankowski R, Wasko J, Mankowski T (2004) Fibres \& Textiles in Eastern Europe, 47:13-18

12. Harwood R, Nusenbaum V, Harwood J (2008) International Conference on Flax and Other Bast Plants Saskaaton Canada 118-128

13. Reme PA, Johnsen PO, Helle T (2002) J Pulp Pap Sci 28:122-128

14. Chinga-Carrasco G, Lenes M, Johnsen PO, Hult EL (2009) Micron 40:761-768

15. Terasaki Y, Noda J, Koichi G (2009) Adv Mat Res 79:235-238

16. Pickering KL, Beckermann GW, Alam SN, Foreman NJ (2007) Comp Part A 38:461-468

17. Andersons J, Sparnins E, Joffe R Wallstrom L (2005) Comp Sci Tech 65:693-702

18. Mehmood S (2009) Unpublished results: Ris $\emptyset$ National Laboratory for Sustainable Energy, Technical University of Denmark, Denmark

19. Charlet K, Eve S, Jernot JP, Gomina M, Bread J (2009) Procedia Eng 1:233-236

20. Kölln K, Grotkopp I, Burghammer M, Roth SV, Funari SS, Dommach M, Muller M (2005) J Synchron Rad 12:739-744

21. Wang HH, Drummond JG, Reath SM, Hunt K, Watson PA (2001) Wood Sci Tech 34:493-503

22. Hill C, Hughes M (2010) J Biobased Mater Bioenergy 4:148-158

23. Thygesen LG, Eder M, Burgert I (2007 J Mater Sci 42:558-564

24. Zafeiropoulos NE, Dijon GG, Baillie CA (2007) Comp Part A 38:621-628

25. Baley C (2004) J Mater Sci 39:331-33

26. Bos HL, Donald AM (1999) J Mater Sci 34:3029-3034

27. Andersons J, Sparnins E (2009) J Mater Sci 44:5697-5705 


\section{Figure captions}

Fig. 1 Optical microscope image of single flax fibre used for measurements of fibre width (Method 1)

Fig. 2 Scanning electron microscope images of flax fibre cross sections used for the measurements of fibre area (Method 2): a) unprocessed image, b) binary image, c) processed image where fibres that were not suitable for measurements were automatically removed

Fig. 3 Schematic drawing of the cross sectional fibre areas that were determined by the two different methods (Method 1 and 2)

Fig. 4 Experimental setup for the tensile testing of single flax fibres

Fig. 5 Frequency distributions of fibre areas that were measured by the two different methods (Method 1 and 2)

Fig. 6 Frequency distributions of the measured a) lumen content and b) aspect ratio of fibres (Method 2)

Fig. 7 Typical stress-strain curves of single flax fibres with experimental errors

Fig. 8 Typical linear and nonlinear stress-strain curves of single flax fibres: a) Green fibres, and b) Cottonized fibres

Fig. 9 Field-emission SEM image of a single flax fibre showing transverse defects and longitudinal defects

Fig. 10 Fracture behaviour of a flax fibre showed a) by optical microscope images of a fibre before and after fracture and b) in a schematic view. The locations of small and large transverse defects are indicated

Fig. 11 Scanning electron microscope image of a large fracture zone in a single flax fibre. Magnified views (1 and 2) are presented to highlight the longitudinal cracks along the fibre, and the formed microfibrillar units at the inner layers at both fractured ends

Fig. 12 Experimental data and model predictions of the ratio between the determined strengths of fibres using the assumed circular cross sections and the measured true cross sections, as a function of the aspect ratio of the cross sectional shape of the fibres

Fig. 13 Representative polarized optical microscope images of single flax fibres: Green fibres (top) and Cottonized fibres (bottom). Fibre defects can be seen as bright and dark lines across the fibres. Used with permission of Mehmood [18] 
Table 1 Mean and standard deviation values of cross sectional area and aspect ratio determined by Method 1 and Method 2 for two large groups of flax fibres (Cottonized fibres)

\begin{tabular}{llccc}
\hline & & & Fibre Counts & Mean \pm stdv. \\
\hline Circular Fibre Area, $A_{\text {circ }}$ & $($ Method 1) & {$\left[\mu \mathrm{m}^{2}\right]$} & 399 & $327 \pm 128$ \\
True Fibre Area, $A_{\text {true }}$ & $($ Method 2) & {$\left[\mu \mathrm{m}^{2}\right]$} & 585 & $236 \pm 115$ \\
Lumen Content & $($ Method 2) & {$[\%]$} & 585 & 1.6 \\
Aspect Ratio & $($ Method 2) & {$[-]$} & 585 & $1.42 \pm 0.26$ \\
\hline
\end{tabular}


Table 2 Mean and standard deviation values of cross sectional area and aspect ratio determined by Method 1 and Method 2 for one group of 6 flax fibres (Cottonized fibres)

\begin{tabular}{ccccc}
\hline $\begin{array}{c}\text { Fibre } \\
\text { Number }\end{array}$ & $\begin{array}{c}\text { Circular Fibre } \\
\text { Area, } \mathrm{A}_{\text {circ }} \\
(\text { Method 1) } \\
{\left[\mu \mathrm{m}^{2}\right]}\end{array}$ & $\begin{array}{c}\text { True Fibre } \\
\text { Area, } \mathrm{A}_{\text {true }} \\
(\text { Method 2 }) \\
{\left[\mu \mathrm{m}^{2}\right]}\end{array}$ & $\begin{array}{c}\text { Relative Area } \\
\text { Difference } \\
\Delta_{\text {area }} \\
{[\%]}\end{array}$ & $\begin{array}{c}\text { Aspect } \\
\text { Ratio* } \\
{[\text { major axis/ }} \\
\text { minor axis] }\end{array}$ \\
\hline 1 & $280 \pm 30$ & $273 \pm 35$ & 3 & $1.14 \pm 0.04$ \\
2 & $280 \pm 17$ & $265 \pm 40$ & 6 & $1.41 \pm 0.14$ \\
3 & $215 \pm 25$ & $194 \pm 5$ & 11 & $1.50 \pm 0.15$ \\
4 & $240 \pm 30$ & $268 \pm 30$ & -10 & $1.80 \pm 0.19$ \\
5 & $316 \pm 20$ & $432 \pm 31$ & -27 & $1.78 \pm 0.17$ \\
6 & $224 \pm 29$ & $356 \pm 15$ & -37 & $1.89 \pm 0.13$ \\
\hline
\end{tabular}

*Aspect ratio of an ideal circular shape is equal to 1.0 
Table 3 Mean and standard deviation values for diameter, tensile strength, Young's modulus and strain to failure for single flax fibres. The results are grouped according to the fibre type and two types of stress-strain curves

\begin{tabular}{llcccccc}
\hline \multirow{2}{*}{ Fibre Type } & $\begin{array}{l}\text { Curve } \\
\text { Type }\end{array}$ & $\begin{array}{c}\text { Number } \\
\text { of } \\
\text { Curves }\end{array}$ & $\begin{array}{c}\text { Fibre } \\
\text { Diameter* } \\
{[\mu \mathrm{m}]}\end{array}$ & $\begin{array}{c}\text { Max } \\
\text { Load } \\
{[\mathrm{N}]}\end{array}$ & $\begin{array}{c}\text { Tensile } \\
\text { Strength } \\
{[\mathrm{MPa}]}\end{array}$ & $\begin{array}{c}\text { Young's } \\
\text { Modulus } \\
{[\mathrm{GPa}]}\end{array}$ & $\begin{array}{c}\text { Strain to } \\
\text { Failure } \\
{[\%]}\end{array}$ \\
\hline \multirow{2}{*}{ Green } & Linear & 30 & $18.9 \pm 4.3$ & $0.29 \pm 0.13$ & $974 \pm 419$ & $31.4 \pm 16.2$ & $3.00 \pm 0.65$ \\
\cline { 2 - 8 } & Nonlinear & 0 & - & - & - & - & - \\
\hline \multirow{2}{*}{ Cottonized } & Linear & 15 & $18.4 \pm 3.0$ & $0.19 \pm 0.10$ & $760 \pm 392$ & $33.1 \pm 11.6$ & $2.27 \pm 0.63$ \\
\cline { 2 - 8 } & Nonlinear & 20 & $19.8 \pm 3.6$ & $0.22 \pm 0.11$ & $641 \pm 314$ & $24.2 \pm 10.7$ & $2.50 \pm 0.48$ \\
\hline
\end{tabular}

* These values are the fibre widths measured by Method 1 
Table 4 Examples of cross sectional shapes of flax fibres and their measured aspect ratios

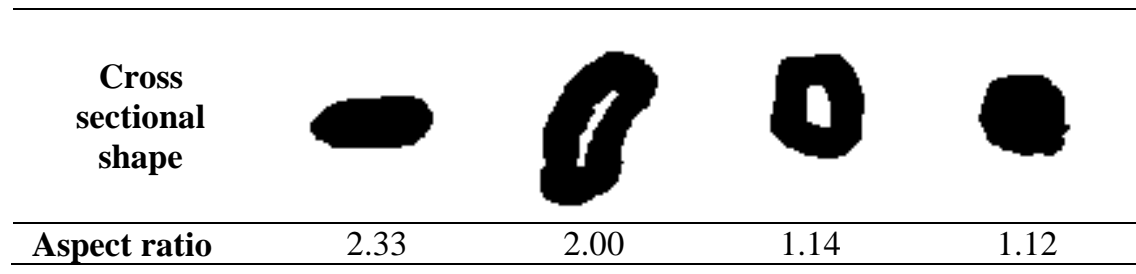


Table 5 Mechanical data from present and previous studies of single flax fibres. Shown are results (mean \pm standard deviation, and coefficient of variation in brackets) of tensile strength, Young's modulus and strain to failure

\begin{tabular}{ccccccc}
\hline \multicolumn{2}{c}{$\begin{array}{c}\text { Tensile Strength } \\
{[\mathrm{MPa}]}\end{array}$} & \multicolumn{2}{c}{$\begin{array}{c}\text { Young's Modulus } \\
{[\mathrm{GPa}]}\end{array}$} & \multicolumn{2}{c}{$\begin{array}{c}\text { Strain to Failure } \\
{[\%]}\end{array}$} & Reference \\
\hline $974 \pm 419$ & $(43 \%)$ & $31 \pm 16$ & $(52 \%)$ & $3.0 \pm 0.7$ & $(23 \%)$ & Present study \\
$760 \pm 392$ & $(52 \%)$ & $33 \pm 12$ & $(36 \%)$ & $2.3 \pm 0.6$ & $(26 \%)$ & Present study \\
$641 \pm 314$ & $(49 \%)$ & $24 \pm 11$ & $(46 \%)$ & $2.5 \pm 0.5$ & $(20 \%)$ & Present study \\
$621 \pm 295$ & $(48 \%)$ & $52 \pm 18$ & $(35 \%)$ & $1.3 \pm 0.6$ & $(46 \%)$ & {$[8]$} \\
$1795 \pm 1127$ & $(63 \%)$ & $76 \pm 40$ & $(53 \%)$ & $2.4 \pm 0.7$ & $(29 \%)$ & {$[9]$} \\
$1339 \pm 486$ & $(36 \%)$ & $54 \pm 15$ & $(28 \%)$ & $3.3 \pm 0.9$ & $(27 \%)$ & {$[25]$} \\
$678 \pm 216$ & $(32 \%)$ & - & - & - & & {$[24]$} \\
$906 \pm 246$ & $(27 \%)$ & - & - & - & & {$[24]$} \\
$1834 \pm 900$ & $(49 \%)$ & - & - & - & & {$[2]$} \\
\hline
\end{tabular}


Click here to download high resolution image

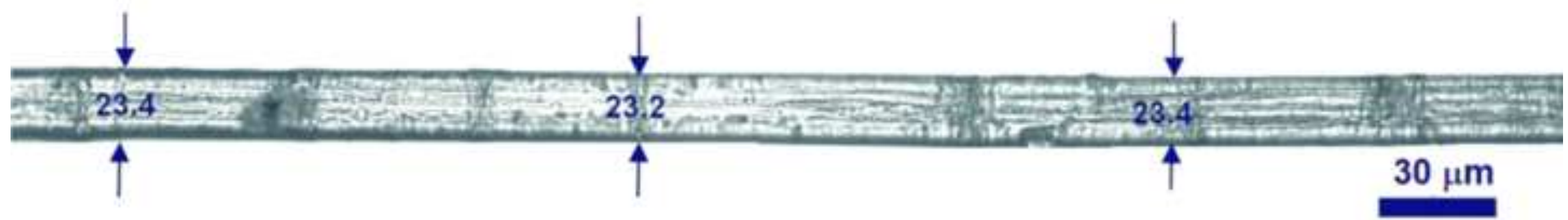




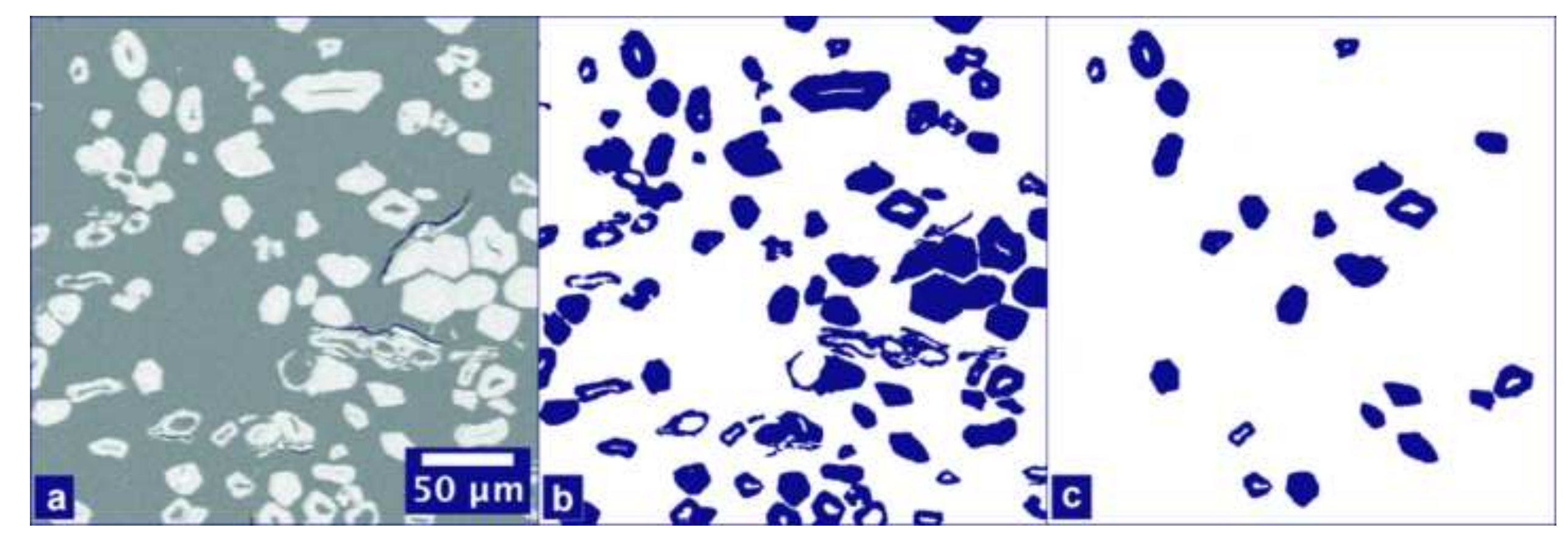

Click here to download high resolution in 


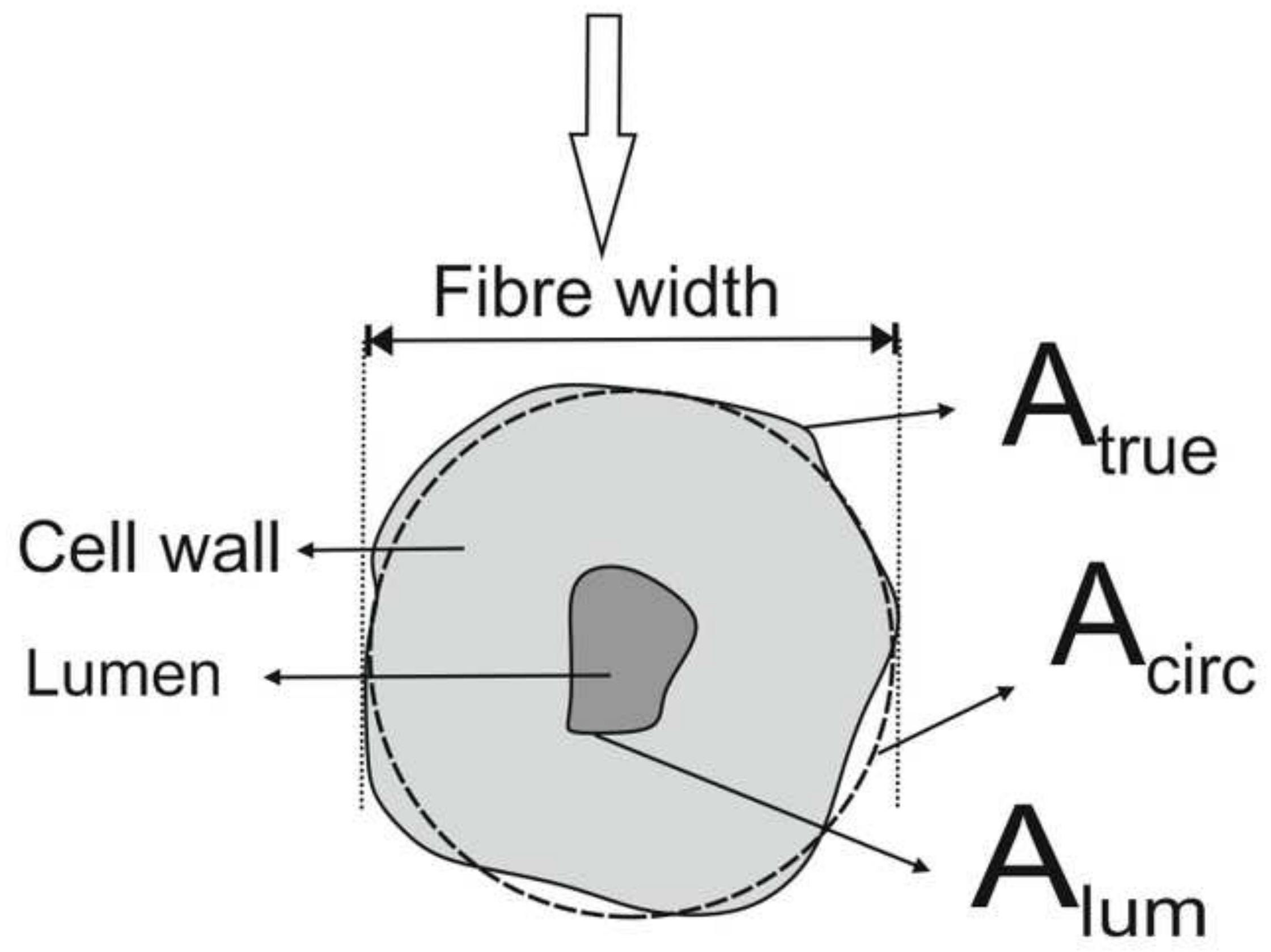



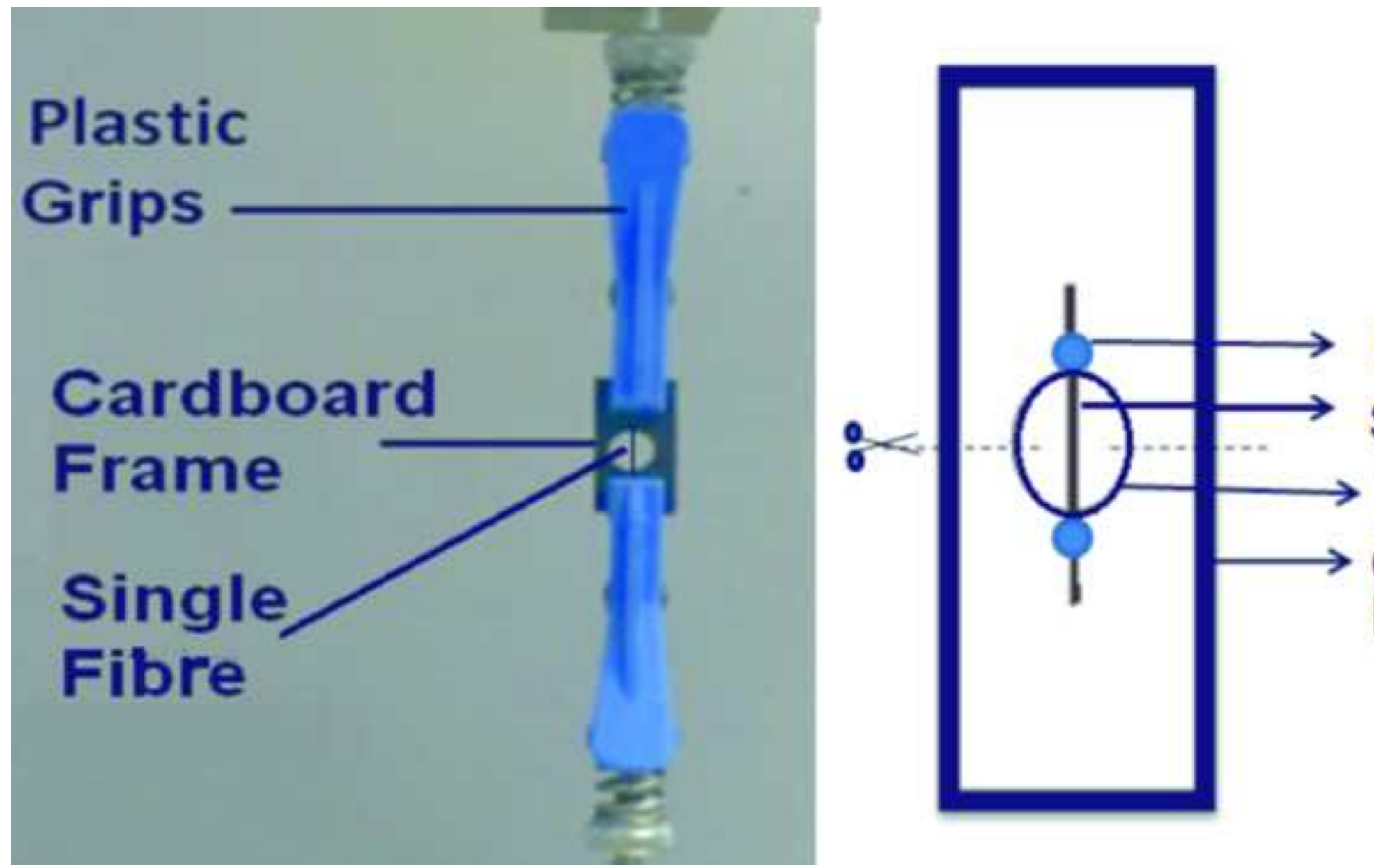

Fixed by Glue Single Fibre Hole Cardboard

Frame

\section{Cardboard} Fibre 


\section{igure 5

Click here to download high resolution image

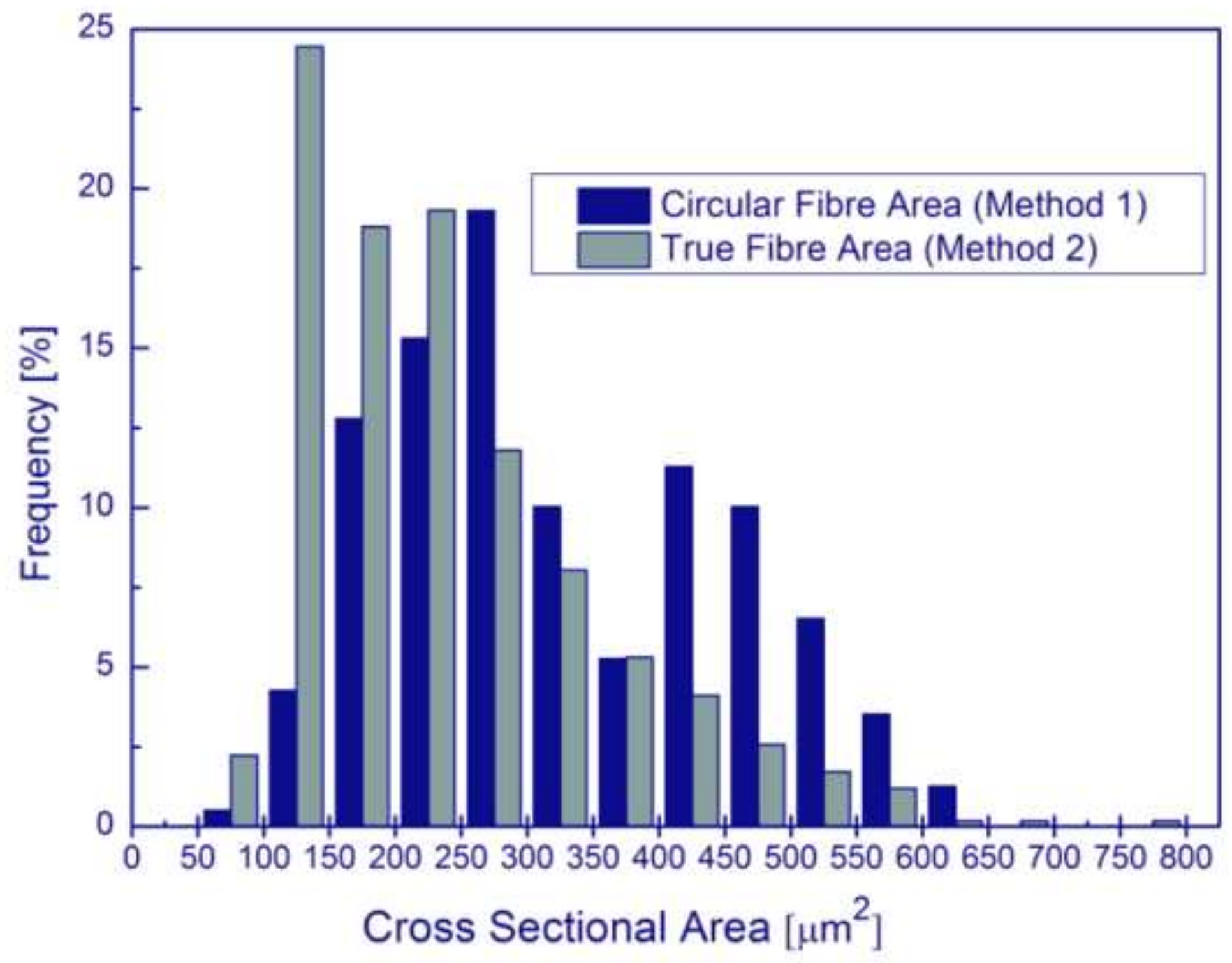


Figure 6

Click here to download high resolution image

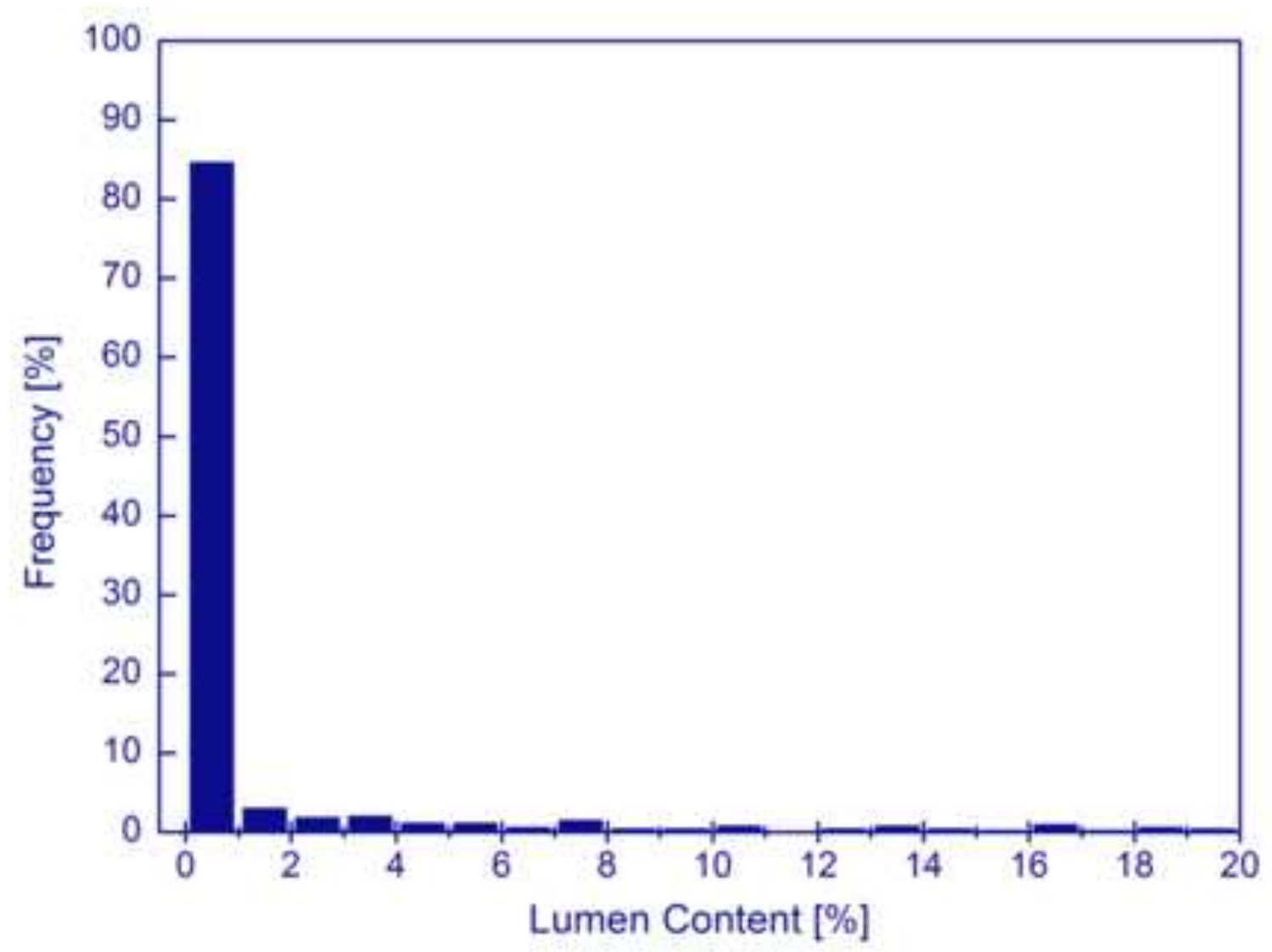

(a)

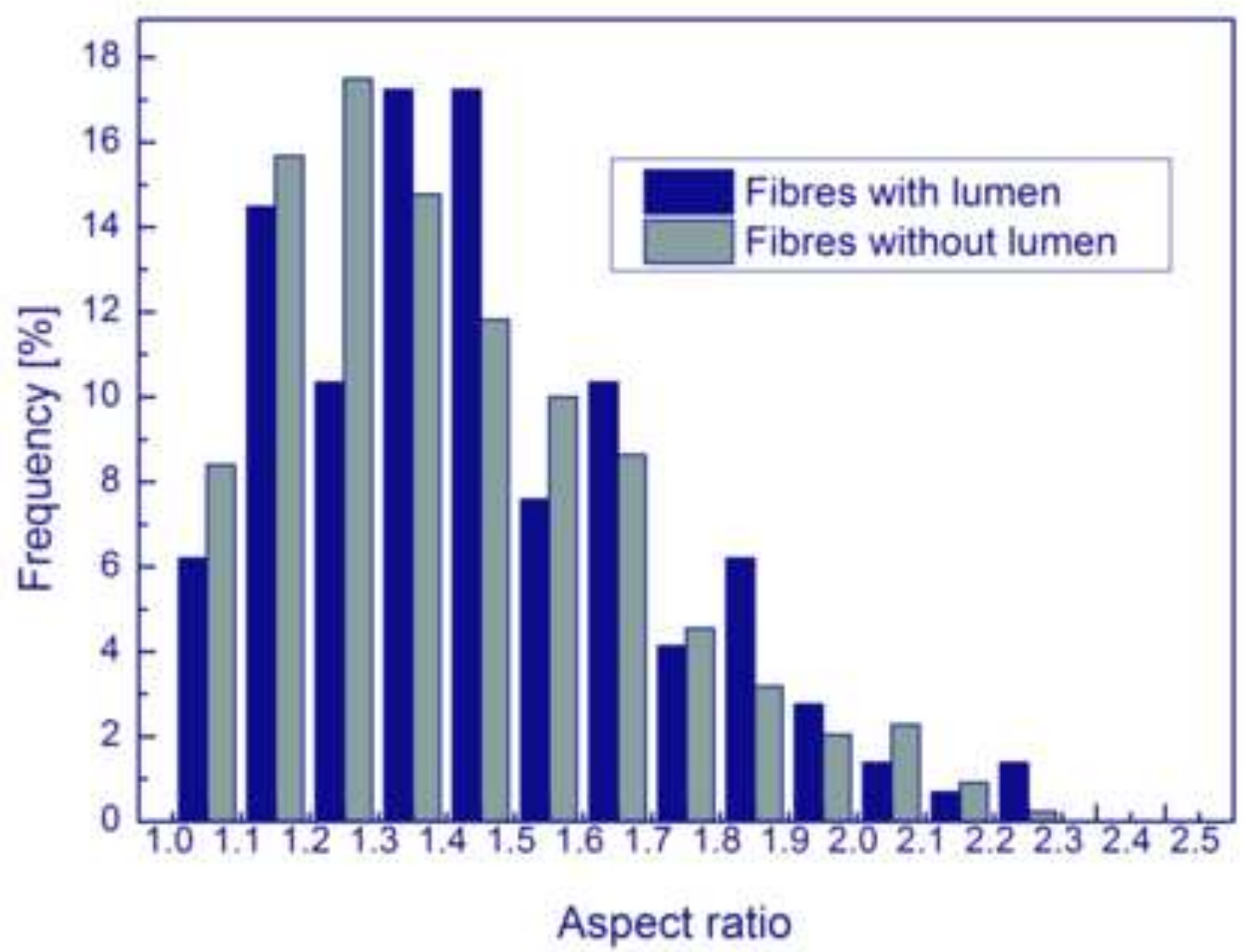

(b) 


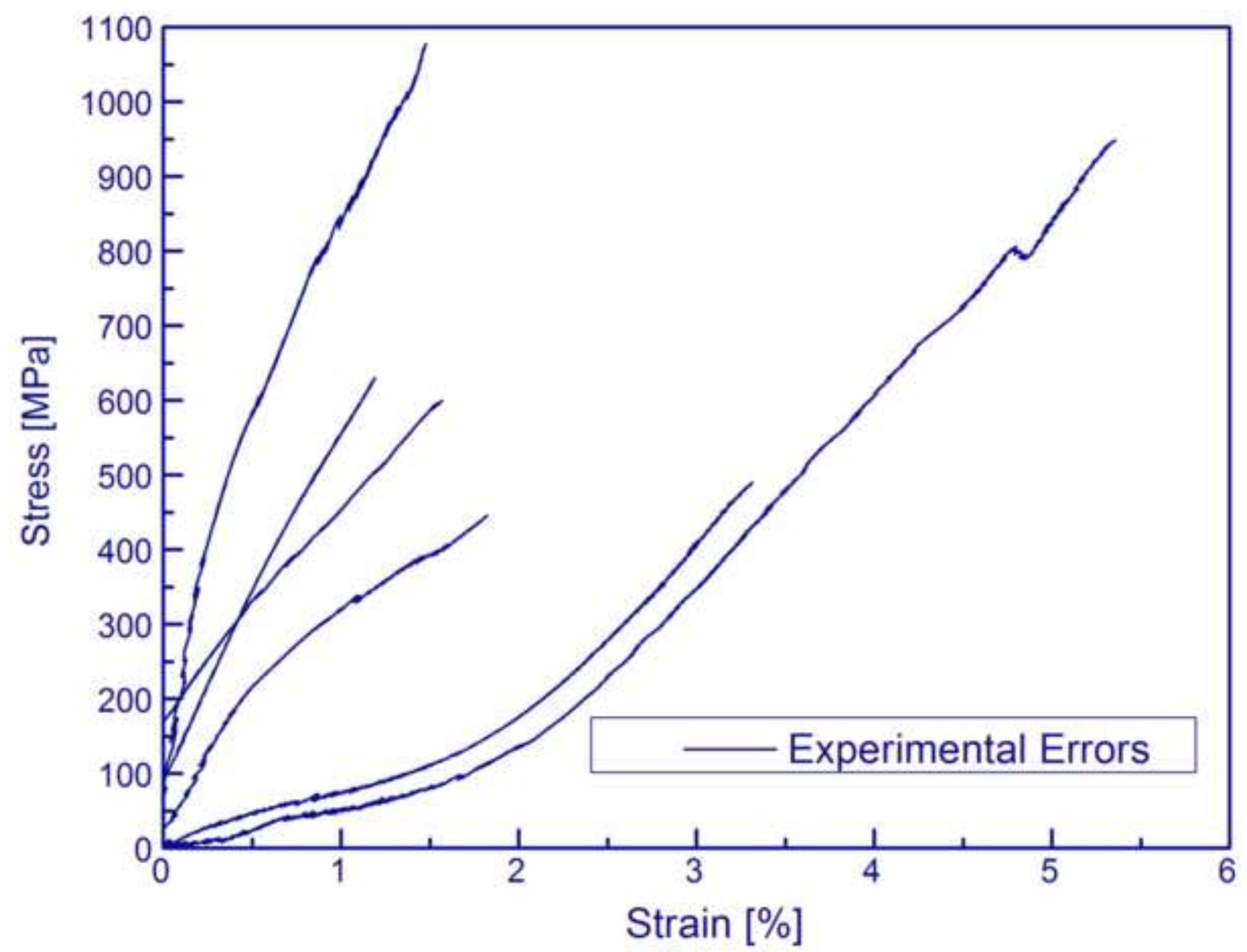


Figure 8

Click here to download high resolution image

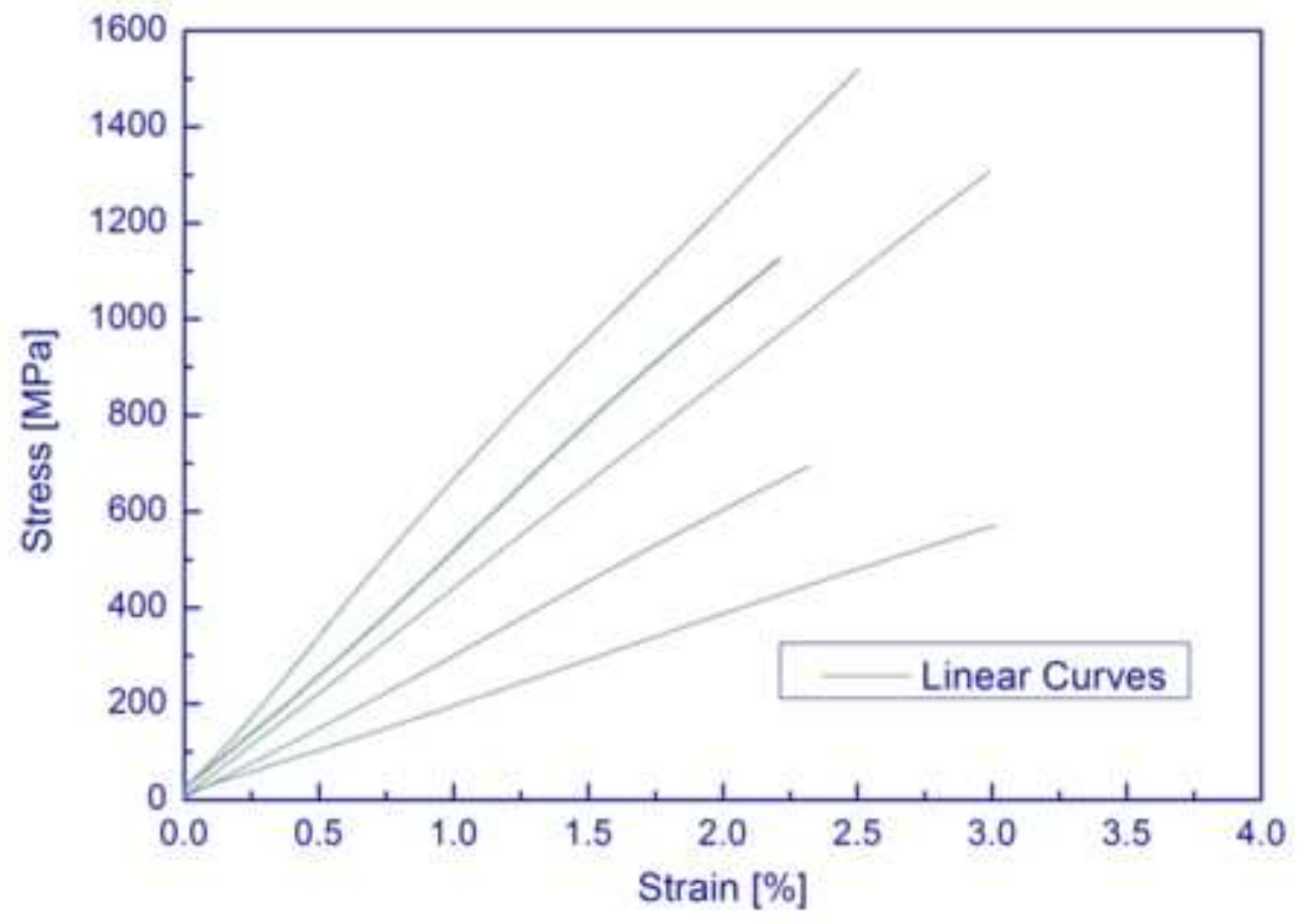

a) Green Fibres

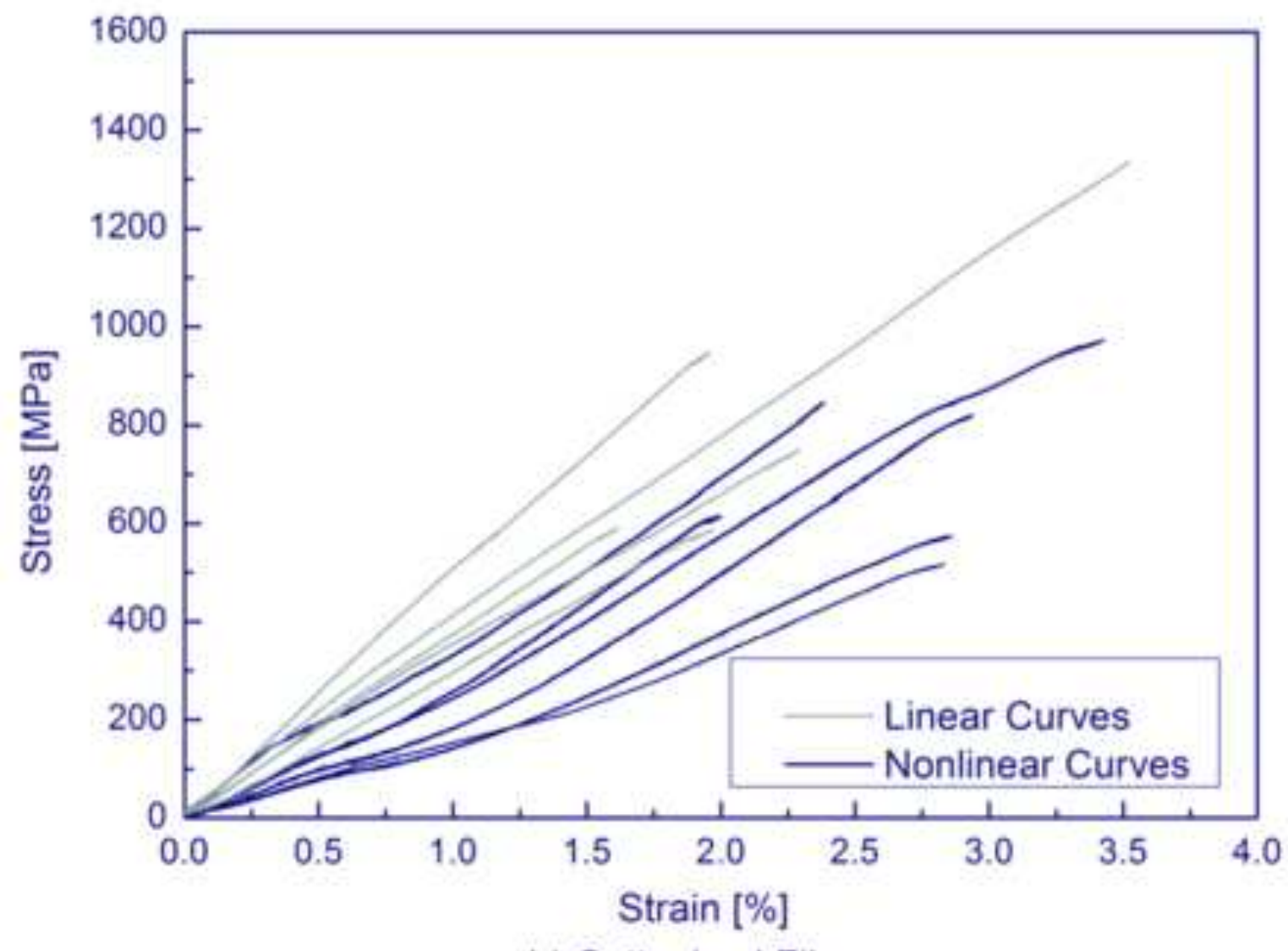

b) Cottonized Fibres 
Figure 10
Click here to download high resolution image
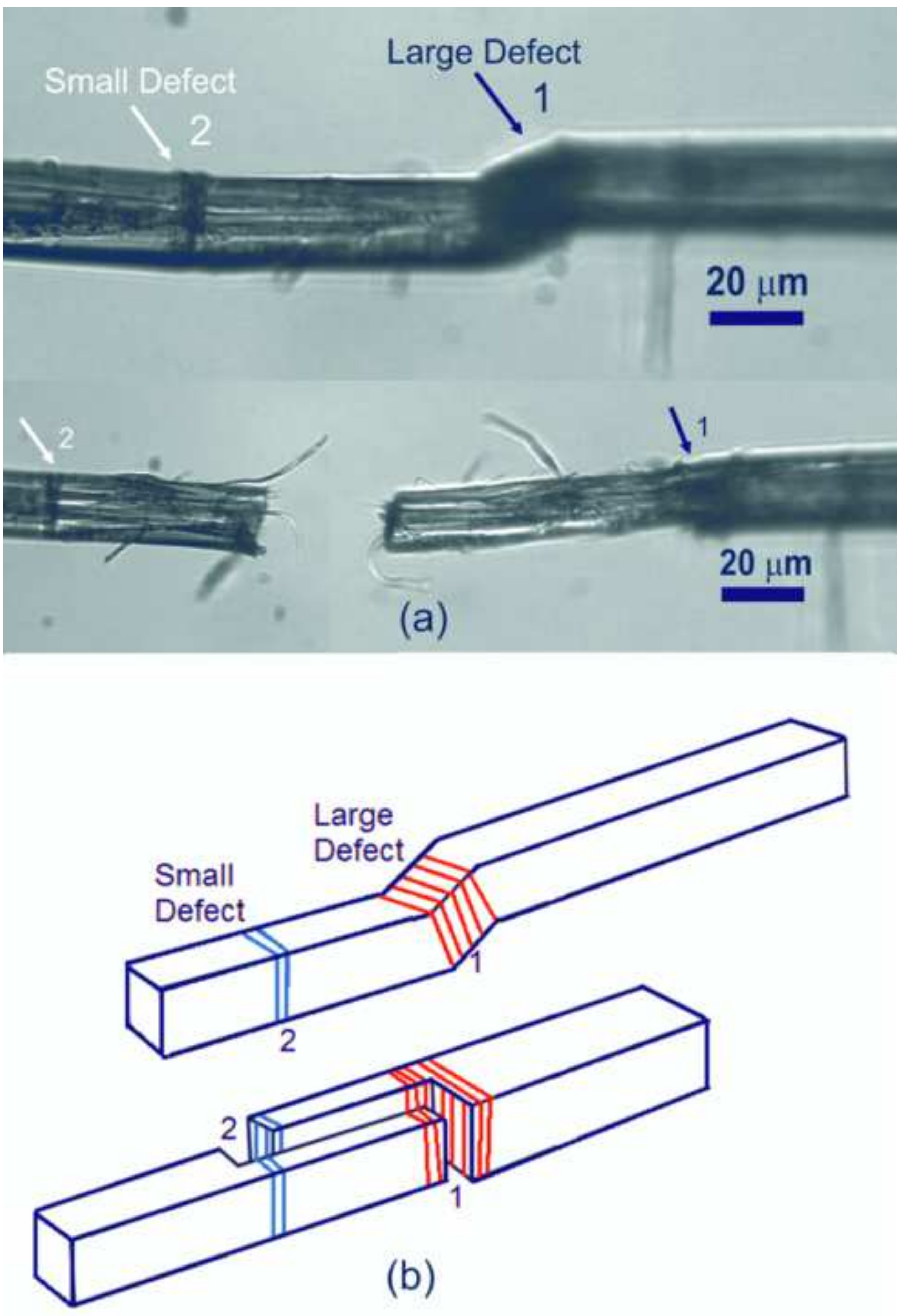
Figure 11

Click here to download high resolution image
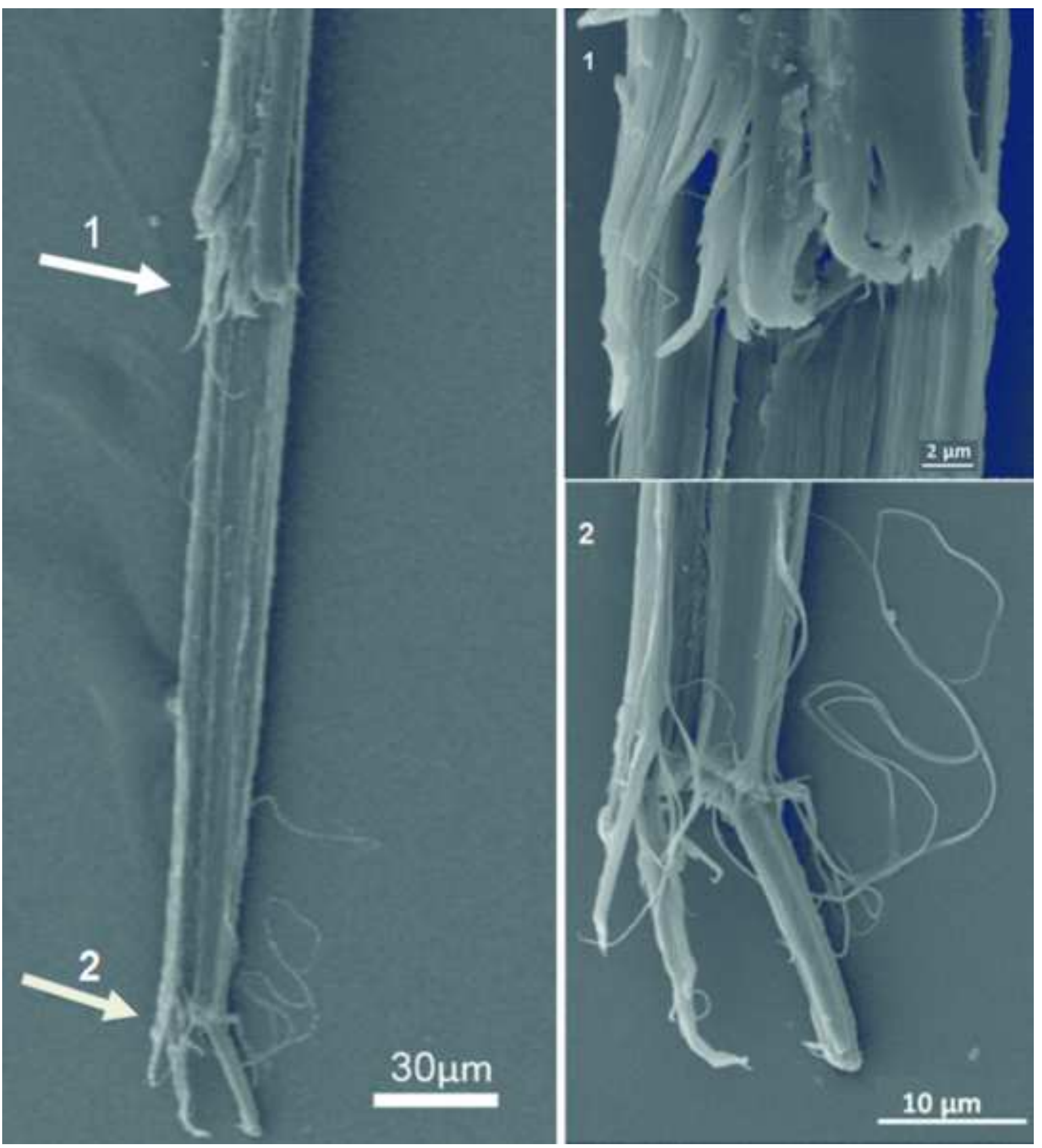

\section{$10 \mu \mathrm{m}$}




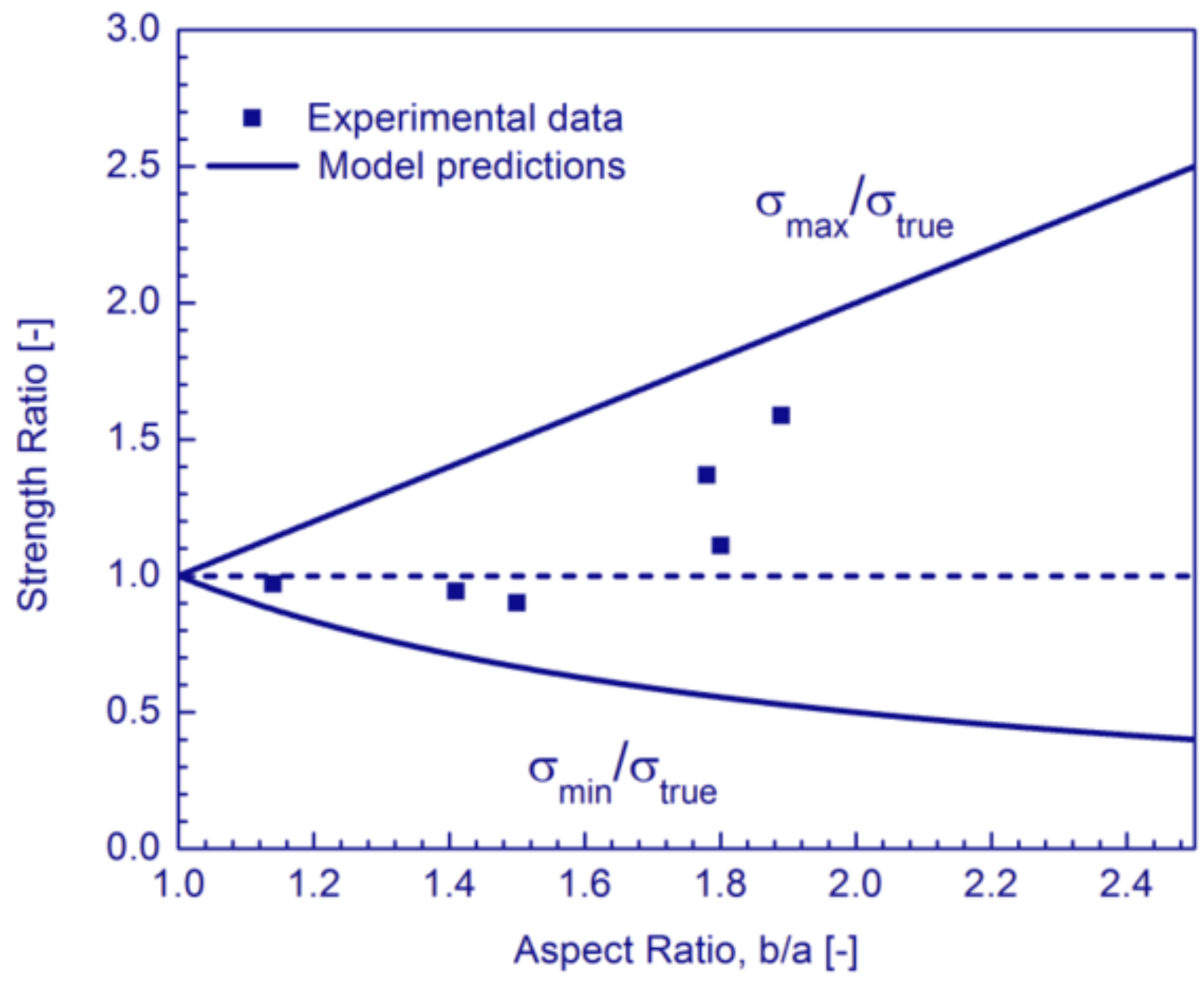


Figure 13
Click here to download high resolution image
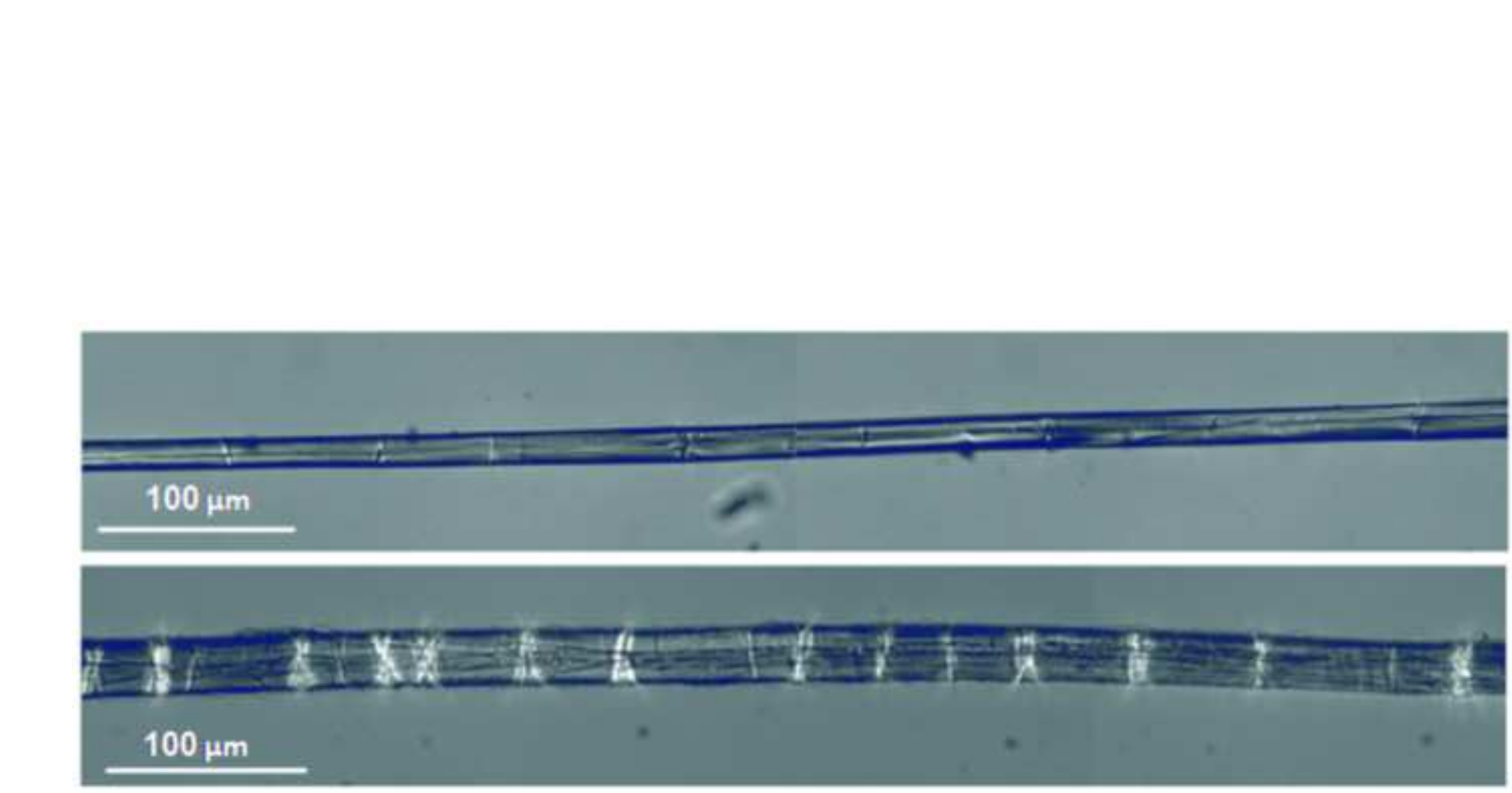

$100 \mu \mathrm{m}$

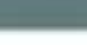

